\title{
Fístula pancreatopleural secundaria a pancreatitis crónica
}

\author{
Pancreaticopleural fistula secondary to chronic pancreatitis
}

Sergio Pacheco ${ }^{1}$, Eduar Murcia ${ }^{2}$, Cristian Díaz ${ }^{1}$, Erick Castillo ${ }^{1}$, Eduardo Briceño ${ }^{1}$, Jorge Martínez ${ }^{1}$, Juan Francisco Guerra ${ }^{1}$ y Nicolás Jarufe ${ }^{1}$

Mujer de 63 años con antecedente de gastrectomía total más esplenectomía por cáncer gástrico hace 15 años. Tras presentar un episodio de pancreatitis aguda evolucionó con derrame pleural derecho persistente e insuficiencia respiratoria. El estudio del liquido pleural reveló lipasa elevada.

Se realizó una resonancia magnética que mostró cambios inflamatorios crónicos del páncreas asociado a fístula pancreatopleural (Figuras 1 y 2). Se realizó una pancreatectomía corporocaudal abierta, seccionando el páncreas a la derecha del eje portal, resecando el trayecto fistuloso (Figuras 3 y 4). Se identificó y ligó el conducto de Wirsung; se suturó el muñón pancreático con prolene $3 / 0$ punto corrido

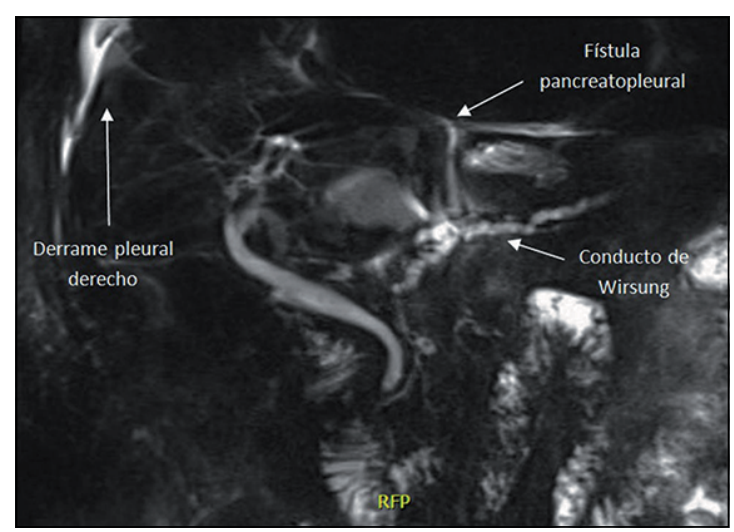

Figura 1. Colangioresonancia que muestra dilatación del conducto pancreático principal, fístula pancreatopleural que se originaba en el cuello pancreático y derrame pleural derecho. y se instaló drenaje tipo Blake. La biopsia informó pancreatitis crónica.

Se retiró el drenaje abdominal, previa cuantificación de los niveles de amilasa. Posteriormente evolucionó con una colección intraabdominal y fascitis necrosante de la pared abdominal, que requirió aseos quirúrgicos y terapia de cierre asistido por vacío. Fue dada de alta para manejo ambulatorio; en controles posteriores no ha presentado derrame pleural.

La fístula pancreatopleural es una complicación severa de las pancreatitis agudas o crónicas ${ }^{1}$. Se presenta en un $0,4 \%$ de los pacientes con pancreatitis $^{2}$. El tratamiento quirúrgico se requiere en una proporción elevada de estos pacientes ${ }^{3}$.

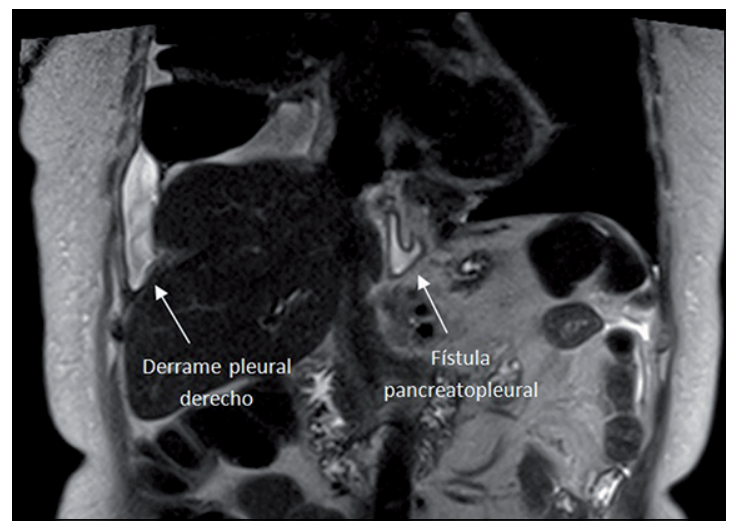

Figura 2. Corte coronal de resonancia magnética que muestra el trayecto de la fístula pancreatopleural (hacia cefálico y posterior, medial al pilar diafragmático derecho) y el derrame pleural derecho.
'Departamento de Cirugia Digestiva, Hospital Clínico, Pontificia Universidad Católica de Chile, Santiago, Chile. ¿Unidad de Pacientes Críticos, Hospital Parroquial de San Bernardo, Santiago, Chile.

Recibido el 16 de enero de 2017; aceptado el 24 de marzo de 2017.

Correspondencia a: Nicolás Jarufe njarufe@med.puc.cl 
Figura 3. Se visualiza la disección completa del páncreas a resecar, con un lazo alrededor del cuello pancreático.

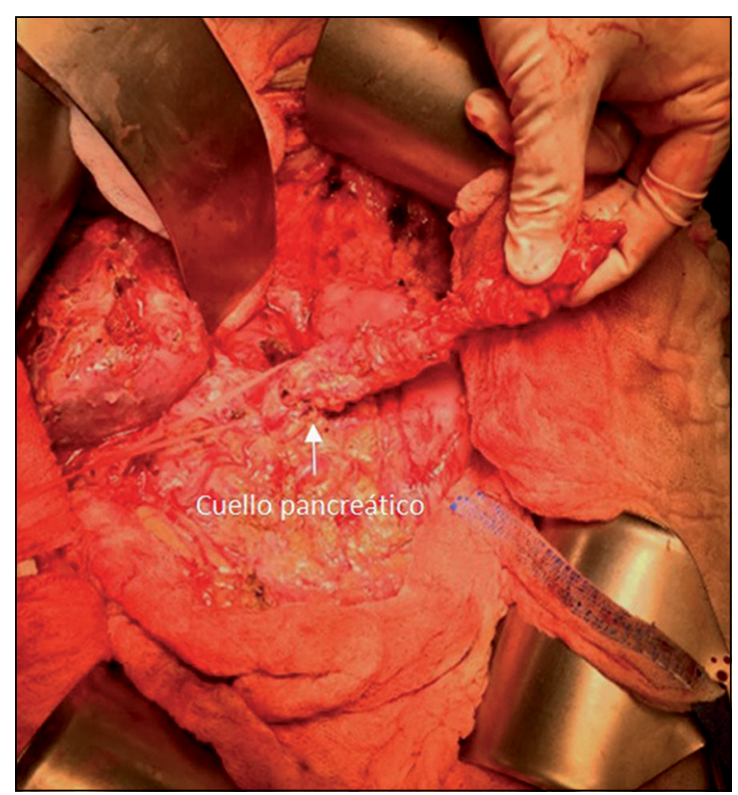

\section{Responsabilidades éticas}

Protección de personas y animales. Los autores declaran que para esta investigación no se han realizado experimentos en seres humanos ni en animales.

Confidencialidad de los datos. Los autores declaran que han seguido los protocolos de su centro de trabajo sobre la publicación de datos de pacientes.

Derecho a la privacidad y consentimiento informado. Los autores han obtenido el consentimiento informado de los pacientes y/o sujetos referidos en el artículo. Este documento obra en poder del autor de correspondencia.

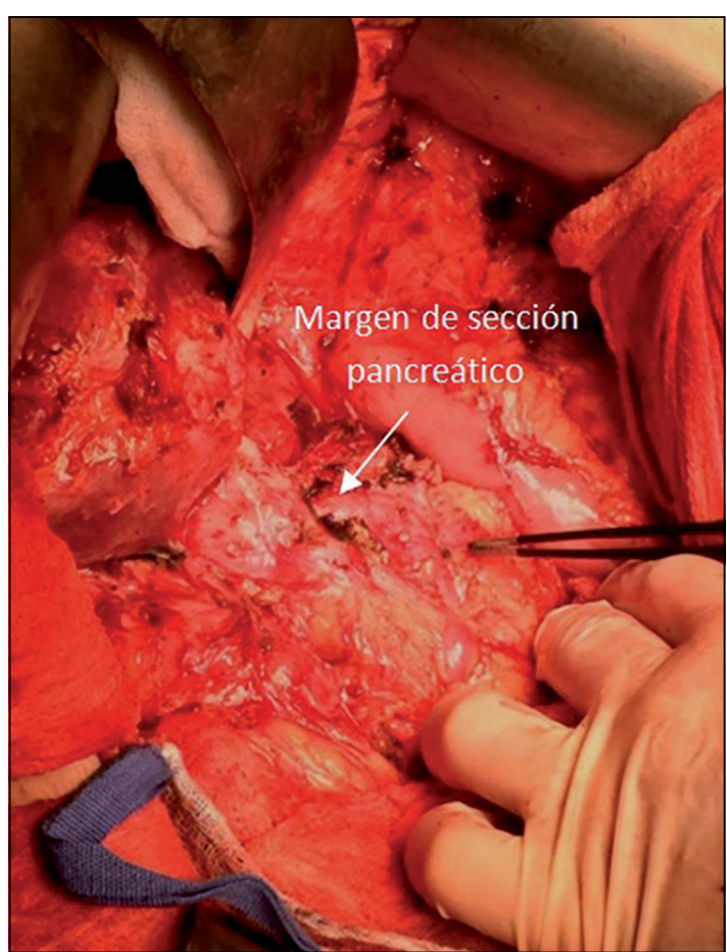

Figura 4. Lecho quirúrgico donde se aprecia el margen de sección pancreático.

\section{Financiación}

El presente trabajo no posee fuente de financiación.

\section{Conflicto de intereses}

Los autores declaran no tener ningún conflicto de intereses.

\section{Bibliografía}

1. Tay CM, Chang SKY. Diagnosis and management of pancreatico-pleural fistula. Singapore Med J. 2013;54:190-4.
2. Ali T, Srinivasan N, Le V, Chimpiri AR, Tierney WM. Pancreatico-pleural fistula. Pancreas. 2009;38:26-31.

3. Schweigert M, Solymosi N, Dubecz A, Ofner D, Stein HJ.
Length of nonoperative treatment and risk of pleural empyema in the management of pancreatitis induced pancreaticopleural fistula. Am Surg. 2013;79:614-9. 